\title{
E se Narciso conhecesse Alice? Conjeturas a respeito de um tema da educação
}

\begin{abstract}
Ormezinda Maria Ribeiro
Palavras-chave: educação;

teorias educacionais; ciências

humanas.

Resumo

Tece algumas conjeturas a respeito dos rumos da educação, apontando como elas são percebidas. Emprega a figura mitológica de Narciso e a personagem Alice, do País das Maravilhas e dos Espelhos, para, numa alegoria metafórica, questionar algumas teorias que têm norteado os caminhos da educação. O propósito é evidenciar o que vários educadores já apregoam sobre esses caminhos e acentuar a premente necessidade do encontro das diversas ciências que convergem para a educação.
\end{abstract}

Não sabemos. Só podemos conjeturar. Karl Popper (1972)

\section{Introdução}

Neste ensaio pretendemos levantar algumas questões, tomando-as não como verdades absolutas, mas como conjeturas que poderão levar à reflexão e ou à refração acerca de algumas teorias que têm norteado os caminhos da educação, e de como elas são percebidas e apreendidas. Não se trata de definir a educação, mas de tentar entender como funciona a educação. Nosso propósito é evidenciar o que vários educadores já apregoam sobre os caminhos da educação e acentuar a premente necessidade do encontro das diversas ciências que convergem para a educação.

Trazemos a figura mitológica de Narciso e a personagem Alice, do país das Maravilhas e dos Espelhos, para, numa alegoria metafórica, tecer algumas conjeturas a respeito dos rumos da educação e de como educadores e educadoras podem traçar seus caminhos na e pela educação.

\section{Mirando o espelho}

Toda ciência é especulação. A verdade não existe em si. Ela depende de algum ponto de vista, poderíamos aduzir das palavras de Popper. O que fazemos a respeito da verdade são conjeturas. E cada ciência chama para si a competência de pronunciar a última verdade. Isso também é relativo, considerando que toda ciência tem como princípio a busca incessante pelas verdades e, se tiver a resposta como absoluta, perderá a razão de ser. Há sempre perguntas a serem feitas, e as respostas são sempre provisórias; portanto, o estatuto de ciência prima por conter uma constante interrogação e uma provisoriedade permanente. Paradoxal, mas estável, essa consideração é que nos faz ainda procurar novas fórmulas, novos caminhos e novas interrogações. 
Brandão (2002, p. 41) nos alerta para essa condição das ciências, lembrando que nas ciências humanas isso ainda é mais forte. Esse antropólogo-educador, dialogando com a história das descobertas, ou conjeturas científicas, aponta inúmeros contextos de certezas e incertezas das ciências, dizendo que andamos sempre às voltas, ora com "psicologismo" demais, ora com "sociologismo" demais. Lembra que há, em alguns casos, "estrutura" em excesso e penúria de "história" e, em outros, o oposto. Afirma que uma "pedagogia da existência" ameaça superar uma "pedagogia da essência" e que, de vez em quando, para sermos construtivistas, construímos mais divergências do que pontos de encontro.

Como educador-antropólogo, questiona o instável lugar de diálogos entre o lugar do sujeito e a dimensão social da educação, assim como a interminável polêmica entre "humanistas" (mas será este o nome mais adequado?) e "behavioristas" (idem?).

A inquietação demonstrada nas interrogações de Brandão aponta-nos para as constantes dúvidas e inconstantes certezas das idéias sobre a psicologia, sobre a pedagogia e sobre os alcances e limites dos olhares das ciências sociais na educação.

Pergunta esse antropólogo-educador:

Somos essencialmente o que a herança genética cria em nós desde um momento para sempre? Tudo o que é importante neste ainda tão pouco conhecido processo de socialização tem a ver com o que se passa na psiquê de cada uma e cada um de nós, e o seu limite seriam apenas as relações interativas de pequena escala, de que a família nuclear é o melhor exemplo e onde a sala de aula é quase um limite? $\mathrm{Ou}$, ao contrário, cada uma de nós, as nossas famílias e as salas de aula que habitamos como estudantes e/ou como educadores são dimensões interindividuais ou agenciadas em e como uma determinada cultura que nos cria, recria e molda com poderes muito maiores do que podemos suspeitar pedagogicamente? (Brandão, 2002, p. 44)

Todos nós, envolvidos com a educação, somos testemunhas da contribuição dos diversos campos da teoria e da prática da educação, mas também somos vítimas dos desequilíbrios e dos modismos que nos arrebatam para as águas de um lago que não sabemos profundo ou não.

E quais têm sido os nossos espelhos? Não raras vezes vemos nossos reflexos em águas não muito límpidas e seguimos refratando ${ }^{1}$ essa imagem projetada por uma construção de uma teoria que nos parece clara. Assim, produzimos nossa compreensão acerca do que lemos, ou ouvimos, reproduzindo imagens, sem considerarmos os múltiplos e ilusórios efeitos dessa projeção. $\mathrm{O}$ espelho nos é favorável. Miramos e vemos refletir uma bela figura. Somos narcisos na educação e nos afundamos nessas águas, sem questionar nosso reflexo. Somos aquela imagem. Não é projeção. Acreditamos cega e surdamente que ali está a verdade. A única e inexorável verdade. A verdade da educação. Como pensamos que não podem existir duas verdades, nesse reflexo de nossas próprias idiossincrasias seguimos em nossa narcísica percepção. Mas seria aquele o único espelho?

\section{Refletir ou refratar?}

Voltamos a Popper (1972): se não sabemos só podemos conjeturar. E retomamos Brandão (2002, p. 42), que acredita existir desequilíbrios muito grandes e muito curiosos mesmo dentro do campo da contribuição das ciências sociais e das ciências humanas. Onde começa uma? Onde acaba a outra? Para esse educador,

[...] existe aí algo semelhante à desproporção entre um excesso de psicologias diferenciais da superfície do humano (psicologia da aprendizagem, psicologia da inteligência, psicologia da motivação, psicologia da personalidade, psicopedagogia, etc.) e uma ausência quase absoluta das psicologias de profundidade (psicanálise, psicologia analítica, etc.).

O que nos leva a esse questionamento é a consciência da necessidade de que os educadores mergulhem cada vez mais no desafio de buscar pensamentos, pesquisas e teorias mais e mais interdisciplinares. $\mathrm{O}$ que não se sabe ainda é por que motivos as descobertas e teorias, a contribuição direta e indireta de Freud, de Jung, de Adler, de Melanie Klein, de Eric Fromm, entre outros lembrados por Brandão, permanecem tão distanciadas da formação de educadores. Não há razão para que essas teorias permaneçam até hoje nas áreas de penumbra da formação e do trabalho de um profissional da educação, afinal, o inconsciente aprende e seus desdobramentos são um
O sentido de refratar é posto
numa relação metafórica projeção de uma imagem. 
fator importante na vida e no destino do sujeito aprendente, reflete Brandão (2002, p. 43):

Ora, pensemos que vista desde uma boa teoria analítica, a pessoa humana é também e é essencialmente um inconsciente que, não apenas nos ternos anos da infância, mas ao longo de toda a vida, projeta símbolos, sentidos de vida, desejos e sensibilidades para além de si mesmo, e constrói assim a sua face de identidade e realização consciente onde, supõe-se, está tudo o que envolve quase toda a capacidade lógica e afetiva de aprender e, portanto, uma boa parte do trabalho da educadora.

Se também ponderarmos sobre isso, veremos que muito do que se tem feito em termos de desdobramentos das teorias sobre a educação tem sido limitado à pura reflexão de seus pensadores e à adoção dessa ou daquela teoria, como adequada ou não, satisfatória ou deficiente, no sentido de dar conta de um campo do conhecimento que, muitas vezes, se restringe a uma mera transmissão de dados repensados à luz de uma dada teoria.

Refletimos? Sim, muitas e muitas vezes. Como uma imagem no espelho, tal qual nossos olhos enxergam, e tal como o modelo se apresenta, com as mesmas cores e as mesmas formas. Na educação espelhamos a imagem, desse ou daquele pensador, dessa ou daquela teoria, que aos nossos olhos ficaria bem em um dado momento de nossas práticas, num dado campo de nossa atenção.

Já disse Sartre que o homem é livre para escolher, mas dentro de determinadas circunstâncias, e que deve decidir-se a fazer algo em cada instante da vida, mas decidirse é limitar-se. Para esse filósofo, conforme registra Larroyo (1974-1979, p. 816-817):

A liberdade é pressuposto ontológico de seu crescimento integral, o qual há de verse à luz de seu destino pessoal. O educando é o criador de sua essência, tem de incumbir-se de si mesmo. O educador, por seu turno, é apenas um suscitador do eu: quem desperta o aluno para a consciência da responsabilidade, da finitude, da morte, mediante uma sustentada preocupação consigo mesmo. O educador não modela a criança e o jovem, pois não pode decidir sua essência; mas terá de incitálo em benefício de sua autenticidade e originalidade pessoais.
Refletir tão-somente sobre esse ou aquele ato educativo não nos basta. O espelho reflete aquilo que se apresenta na sua frente. E o professor não pode, a respeito de sua prática docente, simplesmente refletir, mas deve, sobretudo, refratar. No sentido de não somente contemplar "seu fazer", mas de colocar-se como aquele que se refaz na sua ação de fazer.

Refratar é ir além da imagem projetada, é possibilitar uma nova forma de enxergar uma mesma imagem a partir do reflexo, é somar a partir das divisões, é multiplicar nas subtrações. Refratar é, pois, reconhecer uma reintegração entre as ciências e, até mesmo, entre elas e outras esferas humanas de razão e de sensibilidade como uma saída em direção à descoberta do novo, em todos os campos de criação do saber. O que diria Brandão, "em tempos de inteligências múltiplas, já é bem a hora de multiplicarmos os nossos olhares sobre a inteligência e sobre a própria aprendizagem".

Para Baudrillard (1979, p. 64), o espelho é a absorção, não a reflexão. No espelho que escraviza os que não se livram dele, escreveu Schuler (1994, p. 51), apreendem-se contornos exteriores. Aqueles que se desprendem do encanto dos reflexos inventam o que nunca se viu, em vez de concentrarem-se numa única forma vista, "matriculamse na escola do possível, aprendem a manusear arquivos do passado, a delinear projetos futuros".

À maneira de Alice estão aptos a atravessar o espelho e se aventuram ao estranho, à nova imagem refratada, não refletida, enquanto Narcisos não enxergam além de si mesmos e de suas limitações.

\section{Qual Narciso, qual Alice}

Eis o grande desafio de Narciso: atravessar o espelho e alcançar o universo que rompe com o real criado pelas percepções culturais, conformadas no limite da cultura, dos valores e da ideologia a que se está imerso.

Como Narciso, enfrentamos um dilema: na educação somos espelhos e espelhamos. Narciso encanta-se com o homem idealizado que, tendo capturado a imagem ideal não quis perdê-la e, por se fixar na imagem, recusa o apelo de outras visões, tal qual o homem escravo da caverna. O que vê, como no mito platônico, basta-lhe, captura-lhe a 
vista e o entendimento, destaca Schuler (1994, p. 32).

Qual Narciso, olhamos fixamente para uma realidade refletida pelas nossas próprias ideologias. Construímos nossos signos e construímos com eles nossas "realidades", nossos espaços, e neles habitamos. Se construímos nossa realidade e nossos signos num processo cíclico de reprodução da práxis, somos essencialmente o que as lentes do mundo refletem e refratam em nós. Enxergamos o mundo, ou a "realidade" conformada no mundo, com as lentes desse mundo.

Se entendermos que a linguagem não é só reflexo, reprodução ou reiteração da práxis, mas que ela pode também desenvolver uma ação dialética e criativa, de forma a desagregar os estereótipos de nossa percepção, podemos confrontar Narciso e Alice.

A linguagem que usamos para ler o mundo determina, em grande medida, a forma como pensamos e agimos no e sobre o mundo, uma vez que não existe uma realidade fora da linguagem e dos signos. A linguagem e os signos são constitutivos da realidade, que é produzida na e pela linguagem. Assim, não existe lugar para uma perspectiva que pretenda enxergar além da aparência do discurso. A aparência é a própria realidade, manifesta em discurso, entendendo que, na linguagem, produzem-se compreensões particulares do mundo, isto é, significados particulares. Tal significado é sempre construído, produzido, de forma contextual, no interior de práticas determinadas. Se as práticas sociais são pontos de criação de signos específicos, então a atividade semiótica é produtiva, não uma distorção ou reflexo de uma realidade material que está situada em outro lugar. E virá dela o nosso ponto de apoio, ao conjugarmos (e não haveria outra forma) linguagem e cultura.

Eis o grande dilema de Alice: contemplar o espelho e alcançar a própria face, conhecer o universo interior, desmascarando princípios, valores e crenças, de forma a desestabilizar as certezas, criadas a partir de uma experiência reproduzida diante de um espelho que reflete as algemas das idiossincrasias.

O poder está no exercício da palavra, diz Arendt (1981, p. 45), e todo o campo do saber humano, seja ciência ou ficção, é perpassado por uma linguagem. E é a linguagem que constrói a realidade, embora julguemos realidade geradora da linguagem. Numa perspectiva fenomenológica, não é impróprio repetir Merleau-Ponty (1945, p. 65): "O olho que vê o mundo é o mundo que o olho vê." É inconcebível, portanto, um mundo desprovido de linguagem. Há mundo, porque há linguagem.

A linguagem de Alice é a do questionamento, o da não aceitação do pronto, do já estabelecido. É, sem pretensão de ser, uma atitude filosófica. Alice indaga, questiona. Não aceita o imposto, o suposto ou o pressuposto. Alice atravessa o espelho e se depara com as suas fantasias, com as metáforas explícitas, com a realidade por detrás do espelho. Alice não sabe aonde ir, mas não quer continuar onde está. E procura um caminho. Sabe que a direção a seguir implica escolhas e admite que não tem preferência quanto ao lugar para onde vai. Mas tem certeza de que não quer ficar onde está. É essa certeza que lhe garante a saída.

Qual Alice, numa atitude investigativa, deveríamos atravessar esse espelho, permitir que nossa narcísica vontade ultrapasse nosso reflexo e seja questionada, com a mesma singularidade.

Numa perspectiva culturalista, que combina sociedade, cultura e linguagem e que não acredita na existência de um sujeito soberano e de uma verdade a ser alcançada, e entende que se deve enfatizar a provisoriedade das múltiplas posições em que somos colocados em função das múltiplas mudanças discursivas que nos constitui, inferimos que a linguagem que nos cerca constrói o nosso universo. Somos o resultado dos discursos que nos compõem.

Tivesse Narciso ouvido outras vozes, sua imagem teria se somado às outras tantas. Tivesse Narciso conhecido Alice, uma pergunta ao menos lhe teria sido feita: como posso sair daqui?

\section{Por detrás do espelho}

Conhecer primeiro a si para depois conhecer o outro, no terreno da educação, na relação professor-aluno, é mais do que refletir a máxima socrática, é procurar a transformação das próprias concepções a partir de um olhar interior que se refrata no exterior, na práxis pedagógica, no sentido dado por Cunha (1998, p. 82) como "a prática 
refletida", concebida em unidade com a teoria, "a ação que subsidia o pensamento para a construção de novas idéias e diferentes intervenções da realidade". É sair da posição narcísica e encarar o outro lado do espelho. É, ainda, pensar a prática como uma ação coletiva, técnica, econômica, social, como fundamento e juiz do pensamento teórico, da ideologia, como salienta Lalande (1996, p. 1287). É buscar um diálogo com outras ciências, não um monólogo.

Ante o espelho, Narciso, deslumbrado com o que viu, falou consigo e encantouse, ao perceber a resposta nos lábios da figura admirada. Alice, ao sair de seu mundo, dialoga com um gato. Busca um interlocutor. Sai de si mesma e avança. Ainda que lhe digam que se não sabe aonde vai é indiferente o caminho que venha seguir, Alice não recua. Ao contrário, encanta-se com o que vê pela frente. Faz descobertas. Confere. Compara. Desestabiliza velhas certezas. Alcança novas dúvidas. E não fica onde está. Mesmo quando volta, volta diferente. Diante do espelho não é mais a mesma. Alice, maravilhada, lança-se ao novo destino. Com olhos de ver o mundo. Com atitude filosófica, livre do senso-comum.

É essa a figura que buscamos na educação. Sair do discurso do senso comum e buscarmos na diversidade de pontos de vista o caminho para nossas aprendizagens.

Uma terra-de-todos-e-de-ninguém é o outro lado do espelho, que divide e une cientistas da vida, psicólogos, pesquisadores sociais e educadores. Assim, o mistério do aprender estende-se como nunca a uma possibilidade polissêmica de descobertas e de integrações de idéias empíricas e teóricas. Uma multiplicidade de olhares e de compreensões que pouco a pouco descobre que não há mais caminhos únicos e nem olhares exclusivos. Do outro lado, reconhece-se que não há mais explicações claramente sistemáticas e definitivas para uma verdade única e absoluta. Desfaz-se o mito."A palavra, fundadora, ergue caminhos sobre distâncias. Precários caminhos! Fazem-se e se desfazem; construídos; desconstroem." (Schuler, 1994, p. 8).

Há que se propiciar as aproximações científicas de e entre conhecimentos diversos, em que possa aproximar o senso comum da ciência, em que se busque bem mais a formulação de novas perguntas do que a acumulação de respostas duradouras. Deixar de contemplar as ciências positivas em busca de leis e voltar para as ciências interpretativas à procura de significados. $\mathrm{E}$ isso certamente nos encaminhará para uma convergência fascinante de campos do saber, que nos obrigará a um esforço cada vez mais redobrado de estudos e de pesquisas - já destacava Brandão (2002, p. 43).

Se a imagem fria e congelada de um Narciso perplexo pelo que vê, refletida bem diante de seus olhos, e, posta ao alcance de suas mãos, o paralisa, também nós nos quedamos paralisados diante de imagens que se nos apresentam como uma efígie forte e segura. E, "como negar a verdade da imagem, se tamanha é a força dela?", questiona Schuler (1994, p. 33).

Enfim, como atravessar esse espelho, cujo limite é a nossa própria imagem, que nos paralisa e nos condena à imobilidade contemplativa em nossas idiossincrasias. Como mudar esse reflexo se o que vemos nos basta e se a sombra que projetamos nos captura, sem uma refração? Tal qual Narciso, diante do espelho, queremos imóvel o que todos os dias se constrói.

Lemos em Larroyo (1974-1979) as idéias de Jonas Cohn sobre educação. Nelas depreendemos que, para esse educador, o homem se educa à medida que se apropria dos bens culturais, mas a educação não é mera transmissão de bens culturais. É erro do indivíduo crer que é um ser isolado. Em cada pulsação de nossa vida bate, assim, psíquica, como fisicamente, a vida em comunidade. Então, a verdadeira e mais fecunda formação é adquirida quando o sujeito assimila os bens culturais mediante um esforço ativo, no qual toma clara consciência dos objetivos e resultados de sua ação, quando realiza um esforço por si mesmo, destinado à produção seja espiritual ou manual.

Também em Larroyo (1974-1979, p. 816817) vimos que Sartre, em sua Pedagogia Existencialista, corrobora essa linha de pensamento ao dizer que a existência ou vida humana é, em primeiro lugar, atividade, ação. Existir é, portanto, escolher entre diferentes propósitos ou objetivos; é ir-se fazendo o homem a si mesmo. A existência não é um estado, mas um permanente vir-a-ser.

Se o homem é livre para escolher dentro de determinadas circunstâncias e decidir-se é limitar-se, como praticantes do conhecimento a respeito da pessoa, da cultura e da sociedade, Brandão (2002, p. 46) nos garante que: 
[...] o caminho a percorrer para buscar compreensões passa pela integração e o equilíbrio sempre necessário, sempre instável, entre campos e domínios diversos de conhecimentos científicos. Passa pela interação entre convergências de ciências e outras esferas de saber, sentir e pensar: a filosofia, a espiritualidade, a arte, a imaginação humana em todos os seus campos, em todas as suas dimensões e em todas as suas possibilidades de criação. E passa pela abertura corajosa à indeterminação, à procura incessante de algo sempre nunca inteiramente explicável, porque nunca mecânico e, assim, nunca inteiramente redutível a fórmulas, a números ou a leis.

\section{Algumas conjeturas e outras incertezas no cotidiano escolar}

A educação deixou em algum espelho o reflexo do que tem a ver com as estruturas e relações de reprodução do saber por meio da socialização escolar de crianças e de jovens. A interface com a Antropologia, em algum momento, deixou de ser contemplada. Ecoando Cecília Meireles, poder-seia repetir: "Em que espelho ficou perdida a minha face". Nesse campo, "Narciso e Eco definem os limites do homem: a palavra não atravessa a rocha, os reflexos congelam na imagem." (Schuler,1994, p. 44).

Por algum tempo, considera Brandão (2002, p. 64), "a antropologia deixou em segundo plano até mesmo todo um repertório essencial de questões relativas ao sujeito humano, ao lugar da individualidade na cultura e aos relacionamentos interativos entre pessoas e, não apenas, entre atores sociais". E isso também fez a Educação.

Em que espelho ficaram perdidos os imaginários, as vivências pessoais profundas, os devaneios, as visões de mundo daqueles que vivem e compartilham com outros narcisos o mundo da educação?

A escola deveria devolver ao todo da pessoa a dimensão parcial da função profissional e permitir que as identidades pessoais e profissionais de seus atores culturais, na escola e ao redor da escola, considerados desde o ponto de vista da integridade de suas existências, dentro e fora do exercício de uma função pedagógica do eixo ensinare-aprender, sejam profundamente percebidas. Não só refletidas, mas refratadas.
Por que - perguntaria Alice - a escola se preocupa ainda hoje em ensinar para a prova, ou, num pretenso discurso mais avançado, ensinar para a vida?

Com Brandão (2002, p. 50) questionamos:

Ora, mas não é este reproduzir o outro como eu mesmo o que tem sido hoje em dia bastante revisto e criticado por tantas e tantos educadores? Pois em termos caros ao interacionalismo simbólico, educamos para tornar interior a pessoas uma cultura que as antecede, uma cultura que as conforma e que, em contrapartida, existe nas e através das interações entre as pessoas.

E, como Alice, maravilhada e perplexa diante do que nos parece novo, nos perguntamos: como ensinar o outro como outro?

Se o que existe de mais importante entre nós acontece diariamente e não se pode imobilizar, não podemos continuar querendo imóvel o que todos os dias se constrói. Não podemos congelar essa imagem em nossas bibliotecas, em nossos cadernos amarelados, atendendo ao programa enquadrado em grades curriculares.

Não sabemos: só podemos conjeturar, ecoa a fala de Popper. Mas acreditamos que a resposta para essa interrogação está em nossas aulas. Brandão chamou-a de pequeno milagre, Barthes (1997) tomou-a como tema de sua aula magna no Collège de France, e nós acreditamos que é nela que está o sentido da escola. Não o sentido organizado em módulos, que vão de 45,50 a 75 minutos, mas o sentido revisitado pela Nova Retórica: o do paradoxo e do maravilhamento.

Para tal, os estudiosos do Grupo de Liège, precursores da Nova Retórica, empregam a estratégia dos antigos gregos, professores de retórica que, para arejarem a cabeça dos atenienses contra o discurso do senso-comum, recorriam à técnica de criar paradoxos - opiniões contrárias ao senso-comum - levando seus interlocutores a experimentarem o que ficou conhecido como maravilhamento, ou a capacidade de voltar a se surpreender com aquilo que o hábito foi tornando comum (Abreu, 1999, p. 32).

Baseada, portanto, na diversidade de pontos de vista, na multiplicidade de pensamentos e não em verdades absolutas, a retórica clássica foi combatida, num período coincidente com o desmantelamento da democracia grega. Hoje, a exploração da verossimilhança e dos diferentes pontos de 
vista sobre um objeto ou situação tem sido, diz Abreu (1999, p. 33), o motor que impulsiona o grande avanço da ciência e da tecnologia.

Lembramos também um filósofo francês, Gilles Deleuze, que publicou, em 1969, A lógica do sentido, no qual procura questionar a teoria do sentido estabelecida desde Platão, a partir dos jogos de linguagem de Lewis Carroll, das superfícies das cartas de baralhos que não possuem espessura e são figuras espelhadas e invertidas. Segundo Deleuze, as obras de Lewis Carroll sobre Alice constituem a primeira abordagem aos paradoxos do sentido. A reflexão do espelho conflui com a inversão dos jogos de linguagem carrollianos, e todas essas construções criam um clima de incertezas onde o absoluto não existe.

Qual uma Alice encantada com o que lhe parece novo, perguntamos: por que essa estratégia não pode também ser empregada na educação?

Se avançamos tanto em outros campos científicos, por que reproduzimos velhos modelos em educação? Aqueles mesmos que criticamos e que dizemos retrógrados e ultrapassados? Por que nem ao menos conseguimos nos livrar da grade, das gavetas e dos conteúdos programáticos?

Repetimos, como Eco, as nossas narcísicas expressões, "estamos ensinando para a vida". Mas pouco avançamos, pois vida é aquilo que acontece enquanto planejamos nossas aulas seguindo um ritmo cronológico de acontecimentos passados. Ignoramos o presente, quando projetamos um futuro ideal.

Brandão (2002, p. 65) conclama educadoras e educadores a promoverem a "passagem do cotidiano da escola para a educação do cotidiano", o que, segundo esse educador-antropólogo, significaria, em primeiro lugar, "o abrir as portas da escola e sair a buscar compreender os mundos circunvizinhos, antagônicos, próximos e remotos onde estão, onde vivem e convivem com suas culturas do cotidiano os próprios personagens da vida escolar".

A educação deveria sair de seu terreno cercado e abrir suas portas, sem receio de se re-centrar, de perder seu lugar próprio. É a essa coragem a que nos impulsiona Alice, que, ao sair de seu cômodo lugar, encolheuse, mas permitiu-se o diálogo com outros "seres", arriscou novos caminhos, mesmo sem saber aonde dariam. E, quando retornou, voltou ao seu tamanho, contudo, diferente. Singularmente diferente. Outra, porém, mais madura.

É ao mesmo, no mesmo instante, que nos tornamos maiores do que éramos e que nos fazemos menores do que nos tornamos.

Alice não cresce sem ficar menor, e nem fica maior sem ficar menor. Em todas as coisas há um sentido determinável, como afirma Deleuze (1974, p. 74): "O paradoxo é a afirmação dos dois sentidos ao mesmo tempo."

O mesmo efeito também se dá no campo verbal, do nome que se confunde com o ato. $\mathrm{O}$ acontecimento tem nesse o seu contrário intrínseco. A imagem de Alice guarda seu contrário, que é refletido no espelho. Por várias vezes na história Alice perde o seu nome, seu maior atributo identificador, para dar lugar à série de devires. Alice não é, mas está sendo.

No seu país das maravilhas, não é só seu nome que transmuta. Tudoé metarmorfoseado e metamorfoseável. Até o tempo, senhor de tão intrínseco, perde seu atributo temporal. O chá dos chapelões não devia ser às cinco. Não há tempo para tantas modificações.

Imagine ainda querer chegar em um lugar não importando onde seja esse. Para caber num mundo como esse é preciso encolher-se como Alice. Lembremos Bachelard (1984, p. 197), para quem se encolher pertence à fenomenologia do verbo habitar e para quem acredita que só mora com intensidade quem sabe encolher-se.

Vem-nos aqui outra conjetura: e se, nos lagos da educação, em vez de nos quedarmos diante de nossas projeções, frutos de velhos modelos, fizermos uma nova rede de significados? Busquemos novos símbolos, então!

Se toda a realidade humana é simbólica, ela não é. Apenas representa, sendo representada. Nossas projeções da realidade são, pois, coisas e atos que dependem de simbolização. A capacidade de simbolizar e de produzir símbolos é que faz a diferença entre o animal e o humano, e é o exercício da faculdade de simbolização que cria a cultura que, ao ser reproduzida no seio da vida social, reflete e refrata uma realidade construída pelo homem.

Busquemos nas relações entre pessoas e os seus símbolos e significados, entre uma pessoa e uma idéia, entre as várias possibilidades de realizações culturais dos povos um grande eixo para a educação. 
Indaguemos com Brandão (2002, p. 68): "o que deve mudar na educação, quando a educação é repensada através de todas as suas interconexões socioculturais e não apenas através de suas "funções sociais"?

E à guisa de conclusão, para uma verdade que nos apresenta provisória, busquemos em Michel Foucault (2000) uma resposta também provisória, acreditando com esse filósofo que se deve evitar a alternativa do fora e do dentro, pois é preciso situar-se nas fronteiras.

E, na trilha desse pensador, para quem "o amor à verdade é terrível e poderoso" e que ousou, como Alice, transgredir suas fronteiras, há que se pensar em uma proposta de educação que possibilite um tipo de relação do indivíduo consigo mesmo, que rechace e denuncie a pressuposta universalidade de todo o fundamento, que se constitua sem recorrer a uma verdade única e arraigada nas velhas experiências.

E assim, colocar o sujeito no centro da reflexão, mas um sujeito liberado dos atributos que lhe foram dados pelo saber moderno, pelo poder disciplinar e normalizador e de uma determinada forma de moral orientada para o código, um sujeito da educação, que possa refratar e se multiplicar em incontáveis campos de visão.

Há que fugir do apego à verdade absoluta, da imagem perfeita, e, nessas conjeturas, supor que Narciso será salvo pela mão de Alice.

\section{Referências bibliográficas}

ABREU. Antônio Suárez. A arte de argumentar. Gerenciando razão e emoção. Cotia: Ateliê Editorial, 1999.

ARENDT. Hannah. A condição humana. Rio de Janeiro: Forense-Universitária, 1981. [1958]

BACHELARD, G. A poética do espaço. 2. ed. São Paulo: Abril Cultural, 1984.

BARTHES, Roland. Aula. 6. ed. São Paulo: Cultrix, 1997.

BAUDRILLARD, Jean. Da sedução. Campinas: Papirus, 1979.

BRANDÃO, C. R. A educação como cultura. São Paulo: Mercado de Letras, 2002.

CARROLL, Lewis. Aventuras de Alice no País das Maravilhas e Através do Espelho. Rio de Janeiro: Jorge Zahar, 2001.

CUNHA, Maria Isabel. O professor universitário na transição de paradigmas. Araraquara: JM Ed., 1998.

DELEUZE, Gilles. Lógica do sentido. Perspectiva, São Paulo, 1974.

FOUCAULT, Michel. Arqueologia das ciências e História dos Sistemas de Pensamento. Rio de Janeiro: Forense Universitária, 2000. (Coleção Ditos e Escritos, vol. II).

LALANDE, André. Vocabulário técnico e crítico da filosofia. São Paulo: Martins Fontes, 1996.

LARROYO, F. História Geral da Pedagogia. São Paulo: Mestre Jou, 1974-79.

MERLEAU-PONTY, M. Phénomenologie de la perception. Paris: Galimard, 1945.

POPPER, Karl R. A lógica da pesquisa científica. São Paulo: Cultrix, 1972.

SCHULER. Donaldo. Narciso errante. Petrópolis: Vozes, 1994. 
Ormezinda Maria Ribeiro, doutora em Lingüística e Língua Portuguesa pela Universidade Estadual Paulista (Unesp), Campus de Araraquara, é coordenadora de programas e projetos educacionais da Secretaria de Educação de Uberaba-MG.

ormezinda.ribeiro@uberaba.mg.gov.br

\section{Abstract}

What if Narcissus met Alice? Conjectures regarding a theme in education

In this essay we have considered the aims of education, focusing on how they are perceived. We have employed the mythological image of Narcissus and the character Alice from the books "Alice in Wonderland" and "Through the Looking-glass" in order to question, in a metaphorical allegory, some theories that have guided the paths of education. Our aim is to put in evidence what several educators have already emphasized about these paths, and to point out the urgent necessity of joining the different sciences that converge towards education.

Keywords: education; educational theories; human sciences.

Recebido em 28 de outubro de 2004.

Aprovado em 16 de novembro de 2005. 